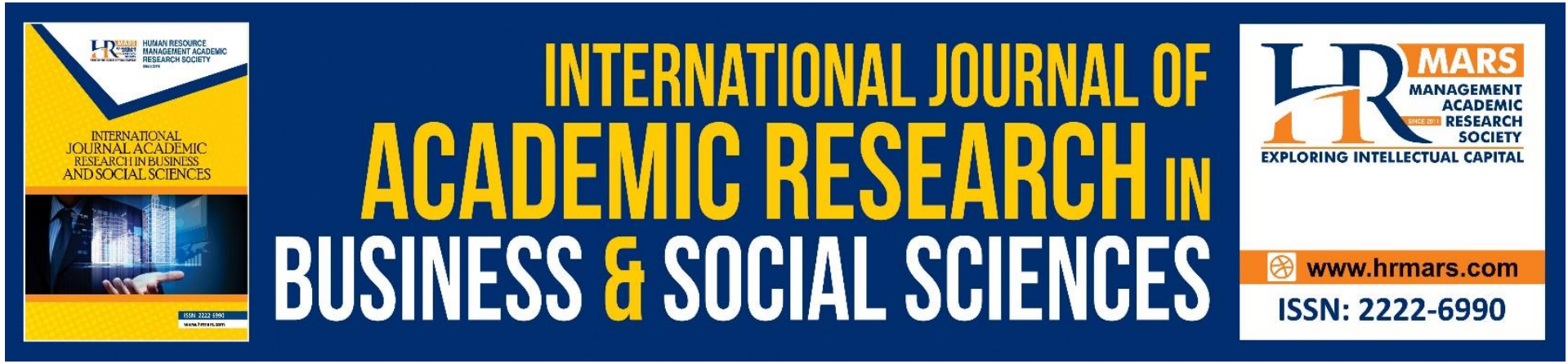

\title{
How Italian Companies Changed Their Communication Strategies During the Covid-19 Pandemic
}

\section{Giuseppe Granata}

To Link this Article: http://dx.doi.org/10.6007/IJARBSS/v11-i9/10774

DOI:10.6007/IJARBSS/v11-i9/10774

Received: 08 July 2021, Revised: 30 July 2021, Accepted: 21 August 2021

Published Online: 05 September 2021

In-Text Citation: (Granata, 2021)

To Cite this Article: Granata, G. (2021). How Italian Companies Changed Their Communication Strategies During the Covid-19 Pandemic. International Journal of Academic Research in Business and Social Sciences, 11(9), 97-106.

\section{Copyright: (c) 2021 The Author(s)}

Published by Human Resource Management Academic Research Society (www.hrmars.com)

This article is published under the Creative Commons Attribution (CC BY 4.0) license. Anyone may reproduce, distribute, translate and create derivative works of this article (for both commercial and non-commercial purposes), subject to full attribution to the original publication and authors. The full terms of this license may be seen at: http://creativecommons.org/licences/by/4.0/legalcode

\section{Vol. 11, No. 9, 2021, Pg. 97 - 106}

Full Terms \& Conditions of access and use can be found at http://hrmars.com/index.php/pages/detail/publication-ethics 


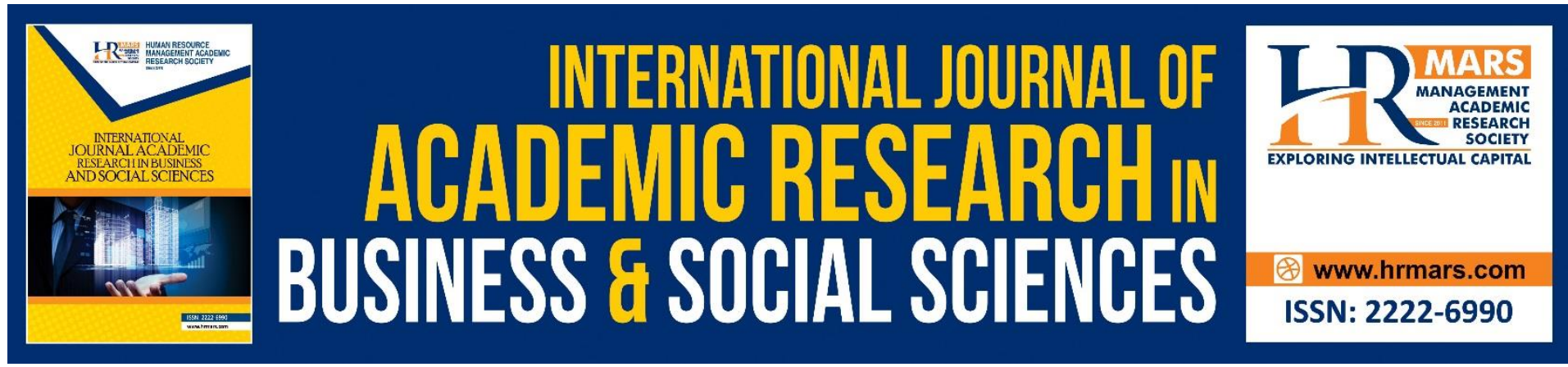

\title{
How Italian Companies Changed Their Communication Strategies During the Covid-19 Pandemic
}

\author{
Giuseppe Granata \\ Departement of Economics, University Mercatorum - Rome, Italy \\ Email giuseppe.granata@unimercatorum.it
}

\begin{abstract}
To analyze the response of companies to the global Coronavirus crisis from the point of view of strategies. To find out how this unintended but undergone revolution affects the way of doing business transforming it from physical to digital one. Even before the pandemic, there was a need for an innovative way for making businesses more agile and flexible by turning to digital technologies, which show progressive but slow growth. The emergency event leveraged social media as the only penetrative tool, promoting the online distribution channel and strengthening the online communication channel. Hence, due to the physical inability to reach the customer and the risks in customer relationships, companies promoted unconventional channels by developing social media advertising. Thus, communication is taking on a one-toone form favored by the emergent context in which companies became closer to social media users turned into potential customers by strategically increasing the visibility of consumer products. Analysis of the statistics showed that between early 2020 and early 2021 more than 2 million new online consumers would emerge in Italy alone, of which 1.3 million turned to digital technologies during the Covid-19 health emergency. This emergency has taught people to combine different digital tools, not only as an opportunity for business renewal, but as a key to sustainability and a starting point for recovery.

In conclusion, companies use digital technology as the only way to survive in times of pandemic. It is a brave and courageous choice and an evolutionary opportunity for communication due to the unexpected evolution.
\end{abstract}

Keywords: Covid-19, E-Commerce, Digital Transformation, Infodemic, Smart Working.

\section{Introduction}

As a result of the public health emergency caused by the spread of a new virus, changes and consequences have also begun to occur at the economic level, putting the global system at risk (Garfin, Silver \&n Holman, 2020).

Coronavirus has not only caused a sharp rise in mortality in all affected countries but it has also dramatically increased the number of people on the brink of starvation.

The World Food Program predicts that the economic impact of the pandemic will globally double the number of people on the brink of starvation, potentially to as many as 230 million. 
Another aspect of great importance is the coronavirus and lockdown impact on businesses. In different ways, businesses have had to cope with the consequences of the temporary closure that have paralyzed the system and the additional costs associated with reopening (Donthu \& Gustafsson, 2020).

Remote working involved almost a quarter of Italian companies during the health emergency: $90 \%$ of large companies ( 250 employees and more) and $73.1 \%$ of medium-sized companies (50-249 employees) introduced or extended smart working during the Covid emergency. The percentage drops to $18.3 \%$ in micro companies (3-9 employees) and $37.2 \%$ in small companies (10-49 employees). According to ISTAT, in the months immediately preceding the crisis (January and February 2020), only 1.2\% of employees were engaged in remote work, excluding companies with no work that can be carried out off company premises. Between March and April this share unexpectedly rose to $8.8 \%$. The proportion of employees working according to agile model increased to $21.6 \%$ in medium-sized companies from $2.2 \%$ in January/February, and accelerated to $31.4 \%$ in large companies from $4.4 \%$ in the first two months of the year. The Covid-19 pandemic represents a profound shock to our economic system, which could even culminate into an economic crisis much worse than the crisis of 2008 (Akhtar at al., 2020). Following the temporary closure of companies, in order to stop the spread of Covid-19 infections, smart models based on new technologies have emerged, leading to new forms of innovation characterised by dramatic and rapid changes that have affected every segment of society.

\section{Companies Are Growing Online}

As soon as the world went into lockdown, the Internet became the main source for entertainment, information and work. Connectivity has become crucial.

Fixed and mobile communications networks have enabled millions of people to keep working, allowed families to keep in touch with loved ones and friends by communicating from home, and facilitated the development of e-commerce. Obviously, the latter was not discovered during the lockdown, but it reached high utilization rates during the emergency period, which represent very interesting opportunities for our economic system. According to analysts, such an increase would have been possible under other circumstances within a few years. Even in Italy, when the pandemic forced Italians to stay home, online usage increased by $33 \%$ in just one week.

Especially in the first phase, the "Stay Home" system led to an increase of up to $80 \%$ in the fixed network and $40 \%$ in the mobile network in the usually less busy 9:30 to 4:30 p.m. time slot.

During this emergency period, new ways and tools for the media usage at the level of individual users and companies were discovered. In Italy, the total value of e-commerce is estimated at 334 billion euro, or 19\% of GDP. 91.9\% of this amount relates to business-tobusiness (B2B) exchange and the remaining $8.1 \%$ to consumer e-commerce (B2C).

Covid-19 has brutally changed the agenda of companies who have seen the potential in digital technology that must not be dissipated in order to get out of the crisis. Whereas non-core activities used to be carried out at the expense of reserves, that were often virtually nonexistent, in the lockdown period they are the only way to restart our economy by containing losses.

According to the Netcomm consortium, despite the impact of Covid-19, e-commerce was the fastest-growing industry of the global economy in 2020. 
We are talking about an increase of $+55 \%$. The second growth industry increased by more than $23 \%$ was modern food retail, i.e. the food distribution via home delivery. With these new types of retail, it is possible, for example, to cook chef's meals at home using kits sold online. In addition to home delivery, there was also a clear growth in the click and collect segment, which is $+349 \%$. The possibility to buy online, pick up physically in-store and skip the line ensures distance and crowd avoidance.

Another tool that has gained a lot of traction is local e-commerce or "neighborhood commerce" promoted by online platforms as well as simple technologies such as Facebook and Whatsapp. In this way, small neighbourhood shops fulfilled a social function by ensuring distribution of products at short notice, staying in contact with their customers and acquiring new ones who had previously turned to large distribution chains (Granata, Moretta \& Tsiakis, 2019).

The Covid-19 emergency has disrupted the daily lives and habits of many people, and consequently all commercial and private activities, as well as all public and private entities. Given the limitations and opportunities of the emergency and viewing digital technology as a key "survival" tool, everyone had to review their social media marketing strategies and develop new ones from scratch (Granata, 2021).

The biggest mistake for companies would have been to suspend all communication activities. Therefore, it was important to maintain contact with customers, or more precisely, the connection between the brand and the audience.

Since the start of the lockdown banning people from going out, users have flocked to the web, seeing digital technology as the only way to stay in touch with others, leading to a significant increase in time spent on social media and consequently, an increase in online shopping.

Like any unforeseen event, the Covid-19 event represents an opportunity for each brand to reinvent itself and becomes a challenge to launch new projects and new content, and to prove that a brand holds up well and can handle the situation.

Companies have implemented new strategies for reaching out to digital users, initiating live sessions and establishing real-time contacts with their community. For instance, a strategy implemented with great success by the NIKE brand, which used real-time marketing to its advantage. In fact, as soon as the Covid-19 emergency happened, the brand tweeted the new motto "Play inside, play for the world", showing that it had been informed about the emergency and reiterating the importance of staying home.

Companies have also used video communication applications to organize or follow webinars and training workshops, always paying great attention to ToV (Tone of Voice) and promoting solidarity initiatives to strengthen Social Corporate Responsibility.

In the past, the availability of mass media facilitated communication with consumer segments rather than with an individual. This concept is challenged by marketing, which emphasizes the centrality of the user by implementing human-centered strategies instead. The main advantage of these strategies is the ability to build customer loyalty, which leads to new and recurring revenues in the medium and long term. Thus, it is one-to-one marketing, i.e. a strategy of personalisation and differentiation of the offer that puts the individual consumer at the centre. For example, Netflix, which recommends certain content for watching based on the user's preferences specified when subscribing to the site, or Amazon, which recommends products to users, taking into account their previous purchases. 


\section{Digital Transformation Concept}

The term 'Digital Transformation' refers to a number of predominantly technological, cultural, organizational, social, creative and managerial changes related to the application of digital technology in all aspects of human society.

By acting in an organic and combined manner on these elements, Digital Transformation goes beyond the mere introduction of new technologies to provide services, deliver goods, live experiences, find, process and make available large amounts of content, regardless of the actual availability of resources (human, material, intellectual, economic, etc.), and creating new connections between people, places and things.

Thus, in the context of the coronavirus pandemic, digital transformation plays the main role in maintaining competitiveness and is considered as a source of survival. Unfortunately, the pandemic has not only infected people, it has also infected societies, revealing their great fragility.

According to researchers, in the very near future we will be facing a completely different and therefore radically changed market. Existing business models will be seriously questioned and some will prove to be completely inefficient and anachronistic. Indeed, forecasters suggest different scenarios. The best-case scenario is to make international supply chains less vulnerable by strengthening the re-shoring phenomenon.

\section{The E-commerce Breakthrough}

In the case of the coronavirus, e-commerce recorded unbelievable numbers. Our daily routines have changed dramatically and, thanks to social distancing designed stop the spread of the epidemic, new habits have emerged, including consumer ones. Fear of leaving home and exposing yourself to the risk of infection and the downed shutters of many shops have led to a boom in online sales. A decisive turning point for e-commerce, which recorded significant numbers in the period from the end of February to the end of June 2020, when there was a surge of more than $80 \%$ in online sales of consumer goods that got in perfect sync with the restrictive measures imposed by the government (Nielsen research).

Even the most skeptical people turned to the internet and online shopping for the first time, as evidenced by flash research from Netcomm, an Italian digital commerce consortium, which found that $75 \%$ of buyers from e-commerce platforms have never done so before.

Therefore, e-commerce should be used to get out of the pandemic, especially in the industries that are experiencing unprecedented growth.

The industry that has benefited most from online sales is Food\&Grocery with turnover from online purchases of essential goods doubling across Italy after 10 March 2020, when the decree making the entire peninsula a protected zone came into force. The Nielsen Institute recorded a $178.1 \%$ increase in online shopping during Easter week. Not just food: sales of over-the-counter medicines and personal care products also rose online (Naja \& Hamadeh, 2020).

At the same time, other strategic industries for Made in Italy recorded a significant drop in turnover. In particular, industries such as fashion and lifestyle, tourism and transport have been hit hard by the anti-visa measures. During the lockdown period, losses in the fashion industry amounted to around $50 \%$ of revenues (estimated by Federazione Moda Italia).

Thus., it is essential to have one's own digital storefront in the world and to implement oneto-one marketing, given that all industries, in order to function online and gain a competitive advantage, have to be efficient and pay more attention to the customer, ensuring human contact and warm communication even at a distance. 
We can consider Covid-19 a huge stress test for e-commerce, exposing all its structural weaknesses. Indeed, we have witnessed an unexpected evolution of the consumption patterns of Italians, and what has changed in record time is, above all, delivery and shipping methods. Click and collect registered $+349 \%$ and we expect it to become a habit in the coming months as it offers flexibility, adaptability to mobility needs and, above all, social distancing. One model that has caught on in Italy during the months of confinement is proximity commerce, which allows the integration of large e-commerce players and small retailers who can reach customers in neighbouring areas through logistics and delivery platforms. However, it turns out that the trend towards single-channel logic is still low, as is the level of shop management through apps that allow customers to find the nearest shop, pay, receive discounts and participate in loyalty programs.

Netcomm's analysis of 280 brands from various industries, representing about 46,000 companies, shows that $79 \%$ have an active e-commerce channel, but only $37 \%$ have the option to pick up or return in-store items bought online.

An analysis of the dynamics of FMCG purchases in the first months of 2020 shows a significant change, especially in March. During the lockdown, an increasing number of Italians started to shop online, but the number of new e-shoppers could have been even higher. Indeed, in the early months of the pandemic, $19 \%$ of households tried to buy products remotely but failed due to the structural limitations of distribution platforms, which experienced an exponential growth in demand within days.

It is not easy to develop the necessary skills to master the world of digital commerce in a short period. It is necessary to fill in one's own digital gaps and to rely on professionals in the field for long-term benefits.

To this end, Google has developed Grow My Store: a free platform that helps companies, especially small and medium-sized companies, identify the strengths and weaknesses of their e-shops. Grow My Store promises to improve your digital storefront for the world: "In these times of uncertainty, we are right there with you to help you run your business.

\section{Transformation and Change in Distribution}

The unexpected impact of the Coronavirus on the economy has undoubtedly destabilized the equilibrium of individuals and companies that were already suffering from the previous economic crisis and found themselves facing new challenges to "stay in the game".

Many socio-economic industries were negatively affected by the pandemic: small businesses and entrepreneurs had to adjust their activities to the models imposed by the health emergency, while others had to comply with the obligations imposed by the rules, which included blocking activities considered "non-essential".

The introduction of restrictions on meetings has actually forced many entrepreneurs to change their business methods and models, creating a new and widespread need for the use of social media, e-commerce and social selling, effectively accelerating digitalization (Lipsman \& Liu, 2020).

The 9th Amway Global Entrepreneurship Report has been one of the most important diagnostic kits on the "health" of self-employment in Italy and worldwide for almost a decade. Its results show, that in the pre-pandemic period, companies with the most entrepreneurial power were located in the centre, followed by those in the northwest, south, northeast and finally the islands. The post-Covid-19 emergency completely changed these results, putting all economic actors of the territory on the same level. The aim of the above-mentioned analysis 
is to analyze the Italian "entrepreneurial spirit" over the past period by combining three behavioral dimensions:

- $\quad$ Skills needed to embark on an entrepreneurial journey

- Feasibility, key resources

- $\quad$ Firmness of decision

Paradoxically, post-pandemic data show an increase in interest in direct selling (about $10 \%$ more than before the pandemic), e-commerce and social selling (about $9 \%$ more than before the pandemic) at the national level. Thus, new digital skills have had a major impact; it has become apparent that promoting one's business through social profiles is the best way to maximize the number of customers and sell one's products.

The entrepreneurial challenge has led to the emergence of new special ways of commerce, through which traders have been able to continue their activities: online sales, food delivery, click and collect in particular.

As a result, the research showed an unexpected growth in Italians' interest in social selling and the use of new digital technologies, which represent a crucial aspect for businesses and individuals that are key to avoid leaving the market due to the current period of uncertainty. It can also be concluded that this new way of doing business will certainly continue to play an increasingly important role in the future of direct selling (Sheth, 2020).

\section{Discussion}

The 1918 influenza pandemic affected a third of the world's population and killed 50 million people. A century ago, medical treatments and countermeasures were considerably limited, and the exchange of information that could facilitate any public health intervention took place mainly by telephone, mail or face-to-face contact.

Now, more than a century later, a new virus has caused a new global pandemic, threatening millions of lives. Many methods of information sharing have been incorporated into giant social media platforms that have incredible speed, reach and penetration. Nearly three billion people use social media regularly and many have been using it for a long time.

There is not yet a full understanding of how these platforms can be used to best support emergency response and resilience.

Obviously, in this context, in the midst of another public health emergency, the history lessons show the importance of understanding how information spreads and how individuals interact. The integration of social media as an important tool for preparedness and recovery can influence the response to COVID-19 and future threats to public health.

Unlike any previous event, WHO has determined that "the outbreak and response to Covid19 was accompanied by the massive "infodemic", an abundance of information - some accurate, some not - that makes it difficult for people to find reliable sources of advice.

Infodemic is an author's word: it was invented by David J. Rothkopf and described in a 2003 article in the Washington Post, named When the Buzz Bites Back. The article describes the development and impact of the SARS epidemic that broke out in China in November 2002, with serious economic, political and security consequences not only in China but also globally, that were out of all proportion to the actual impact of the disease.

The metaphor of an "information epidemic" is not limited to infectious diseases, but is also applicable to communication about terrorism and other events affecting the public. 
Rothkopf is convinced that studying the dynamics of infodemics helps to prevent and contain the spread of fake news and misinformation and to counter it with targeted facts and campaigns to limit economic, political and social damage. Risk communication strategies are used to manage infodemics.

The authors of a recently published study "The Novel Coronavirus (COVID-2019) Outbreak: Amplification of Public Health Consequences by Media Exposure" affirm that, while journalists and public health officials worked to communicate information about risk assessments and recommendations across, there was an accompanying threat in the form of psychological distress resulting from repeated media exposure to news about the outbreak.

Media reports on data released on 2 February 2020 by the World Health Organisation about the coronavirus outbreak repeat the term "infodemic" described as "an abundance of information - some accurate, some not - that makes it difficult for people to find reliable sources of advice".

However, given without further explanation in conventional communications, it does not provide an adequate understanding of the concept of infodemics. Thus, an infodemic is a metaphorical "epidemic" of false or misleading information that spreads with the large-scale spread of an infectious disease.

The recently published article The "coronaviral" infodemic (Galletti, 2020) also gives us an overview of what the term means, providing insights into how and where reliable and validated information can be found.

Infodemics spread rapidly through social and other digital media; pseudo-experts multiply, increasing confusion, anxiety and panic; dangerous situations can arise where the public is reluctant to follow the advice of health authorities, to the extent that the effectiveness of planned interventions may be undermined.

This has implications for not only the immediate suffering of a population already struggling with an unprecedented health problem and the resulting economic consequences, but also for the long-term physical and mental health effects.

\section{Conclusions}

In conclusion, this data analysis shows that Covid-19 is the equivalent of a humanitarian crisis. An epidemic that has imposed an unprecedented global crisis on the entire world with disastrous consequences in terms of health, culture and economy.

We feel ambivalent about using social media. On the one hand, we think they can be a very important resource, if they are used to access a range of materials, to share data and information in all fields. On the other hand, we do not support the idea of fake news and subsequent infodemic, and we consider the mass use of the Internet a form of controlling people's profiles as well as their minds.

The post-Covid world will be characterised by a very different way of daily life style, living together, studying and working. Social and digital technologies will be widely used, and digital technologies will continue to be part of our lives.

Many people have found that digitising many everyday tasks can help improve their productivity, and others will keep using e-commerce because it is more convenient and easier to use. Many companies have implemented new digital strategies to cope with this terrible period. Thus, communication strategies have changed, as have all the activities of a digital presence.

Companies will take advantage to reduce costs and replace the physical employee with a digital entity. 
However, abandoning the old models of work and learning is unlikely to return to the preCovid phase. This is the "new normal" in which a new culture and organisational mentality is created.

In terms of economic fragility, forecasts show that at the end of this pandemic, the effects of the virus will be devastating. The measures already approved to support workers and businesses will not be enough. What is needed is an injection of liquidity for businesses, support for exports, increased public investment, and, above all, innovation and new industrial strategies that will be focused on strategic production.

Nevertheless, the emergency is the driving force behind the largest smart-working experiment ever undertaken in Italy. In these circumstances, everyone will face a reorganization of their working time and space, which is no longer rigid in the current technological transformation. Therefore, we face the challenge of helping people develop the skills and competencies to handle these changes, to regain a sense of the limits of our vulnerability as a value and the ability to rely on our own strengths. These strengths can be enormous, especially if we will learn to cooperate, to help solve each other's problems as if they were our own.

Overall, this research clearly shows that there is a massive attraction of digital technologies letting us to look forward to a "different normalcy", albeit at a distance even in this emergency. 2. Research is meant for contribution. Please add a paragraph after conclusion, which details the theoretical and contextual contribution of this research. How is it significant to the existing knowledge and how it plays its role in context?

\section{Theoretical and Contextual Contribution of this Research}

This research work aims to understand how, in the period of the global pandemic, businesses and consumers have had to revolutionize their behavior. Business strategies have changed and consumer purchasing methods have changed. Some marketing functions have changed such as distribution and communication. Thanks to digital, companies have been able to continue selling, delivering and satisfying customers. While for consumers, thanks to digital they have been able to continue shopping and obtaining products at their homes. This is demonstrated by research where there has been a very strong increase in digital techniques in reference to online purchases, for example.

Ultimately we can say that if the Covid19 Pandemic has brought very negative events to the world, from the digital point of view it has given a boost by realizing what in other periods would have taken years.

\section{References}

Akhtar, N., Akhtar, M. N., Usman, M., Ali, M., \& Siddiqi, U. L. (2020), COVID-19 restrictions and consumers' psychological reactance toward offline shopping freedom restoration, The Service Industries Journal, vol. 40, no. 13-14, pp. 891-913 Doi: 10.1080/02642069.2020.1790535.

Donthu, N., \& Gustafsson, A. (2020). Effects of COVID-19 on business and research. Journal of Business Research, 117, pp.284-289. Doi.org/10.1016/j.jbusres.2020.06.008

Galletti, G. (2020), L'infodemia coronavirale, ARS - Toscana

Garfin, D. R., Silver, R. C., \& Holman, E. A. (2020), The Novel Coronavirus (COVID-2019) Outbreak: Amplification of Public Health Consequences by Media Exposure.

Health Psychology, Advance online publication. Doi:10.1037/hea0000875 
Granata, G., Tartaglione, M. A., Tsiakis, T. (2019) Predicting Trends and Building Strategies for Consumer Engagement in Retail Environments, IGI Global Usa. ISBN13: 9781466684591 EISBN13: 9781466684607. Doi:10.4018/978-1-5225-7856-7.

Granata, G. (2021). The Digital Evolution of Consumer Purchasing Methods and the Impact on Retail. International Journal of Academic Research in Accounting Finance and Management Sciences, 10(4), 1-7. Doi:10.6007/IJARAFMS /v10-i4/8429.

Lipsman, A., \& Liu C. (2020), US Ecommerce: Coronavirus Boosts Ecommerce Forecast and Will Accelerate Channel-Shift, eMarketer. Available: https://www.emarketer.com/content/us-ecommerce-2020.

Naja, F., Hamadeh, R. (2020), Nutrition amid the COVID-19 pandemic: A multi-level framework for action. European Journal of Clinical Nutrition, 74, 1117-1121. Doi 10.1038/s41430020-0634-3

Sheth, J. (2020), Impact of Covid-19 on Consumer Behaviour: Will the Old Habits Return or Die? Journal of Business Research, 117, pp.280-283. Doi 10.1016/j.jbusres.2020.05.059. 